\title{
Problematic social networking site usage and substance use by young adolescents
}

Alessandra Buja ${ }^{1 *}$ D, Luigi Gallimberti ${ }^{2}$, Sonia Chindamo ${ }^{2}$, Camilla Lion ${ }^{1,3}$, Alberto Terraneo ${ }^{2}$, Michele Rivera ${ }^{4}$, Elena Marini ${ }^{2}$, Luis Javier Gomez-Perez ${ }^{5}$, Emanuele Scafato ${ }^{6,7,8}$ and Vincenzo Baldo ${ }^{9}$

\begin{abstract}
Background: Substance use and abuse by young adolescents has become a serious issue for public health services, and several socio-environmental factors can influence how vulnerable a young adolescent may be to their appeal. The present study was devised to examine whether substance use in early adolescence is associated with problematic social networking site usage (PSNSU).
\end{abstract}

Methods: In the academic year 2013-2014, secondary schools in Padua (north-eastern Italy) were involved in a survey called "Pinocchio". A sample of 1325 pupils attending years 6 to 8 (i.e. aged from 11 to 13 years) completed self-administered questionnaires, in which PSNSU was measured by applying the DSM-IV criteria of dependence to identify any social network addiction disorder and its fallout on daily life. Multivariate analysis (ordered logistic regression) was performed to assess an adjusted association between young adolescents' substance use and PSNSU.

Results: The percentage of pupils classified as problematic social networking site users rose with age (from 14.6\% in year 6 to 24.3\% in year 7, and 37.2\% in year 8), and it was higher in girls (27.1\%) than in boys (23.6\%). In a fully-adjusted model, PSNSU conferred a higher likelihood of being substance users (OR 2.93 95\% Cl 1.77-4.85).

Conclusion: This study identified an association between PSNSU and the likelihood of substance use (smoking, alcohol and energy drink consumption), providing further evidence of the need to pay more attention to PSNSU in early adolescence.

Keywords: Substance use, Adolescents, Problematic social networking site usage, Alcohol consumption, Energy drink consumption, Smoking

\section{Background}

Substance use and abuse by young adolescents is seen by public health services as a real cause for concern. Some of the socio-environmental factors that typically make children and young adolescents more or less vulnerable to substance abuse - such as peer pressure, and school and/or family environments - have already been thoroughly examined. There are other factors, however, that may have the potential to induce substance abuse [35], such as modern information and communication technologies, and particularly one that is very popular among adolescents, i.e. social networking sites (SNSs).

\footnotetext{
* Correspondence: alessandra.buja@unipd.it; http://www.alessandrabuja. altervista.org/index.html

${ }^{1}$ Department of Cardiologic, Vascular, Thoracic Sciences and Public Health, University of Padova, Via Loredan, 18, 35131 Padova, Italy

Full list of author information is available at the end of the article
}

In America, $76 \%$ of all people aged 13 to 17 use social media. Facebook is the dominant platform, with $71 \%$ of all adolescents using it. Instagram and Snapchat have also become increasingly popular, with $52 \%$ of teens using Instagram, and $41 \%$ using Snapchat. One in three American adolescents use Twitter and another one in three use Google Plus.

SNS usage provides new opportunities for exposure to unhealthy substances [36] because they are advertised more and more often on digital media, even among adolescents [45]. The content that adolescents report viewing on SNSs usually concerns pictures and comments posted by their friends [39], and researchers have found that as many as $25-37 \%$ of older teenagers post details about their alcohol drinking [38]. The content of such posts may give adolescents the impression that substance use as a

(c) The Author(s). 2018 Open Access This article is distributed under the terms of the Creative Commons Attribution 4.0 International License (http://creativecommons.org/licenses/by/4.0/), which permits unrestricted use, distribution, and 
normative behavior among peers of the same age and older. Compared with those who see alcohol use portrayed less frequently, adolescents who gain the impression from their elder peers' Facebook profiles that it is normal to drink alcohol are at higher risk of developing an attitude shown to predict alcohol use [33]. SNS usage has become ever more popular and common, even to the point of giving rise to a clinical disorder associated with abuse-like signs, such as an excessive, compulsive online social networking. Several authors have claimed in recent times that this becomes a sort of behavioral addiction [3], and some argue that addiction to SNSs has grown since the latest technologies (tablets, smartphones) arrived on the scene [2]. It is still difficult to find reliable statistics concerning the prevalence of SNS addiction, however [20]. Studies on addiction to Facebook have focused mainly on samples of undergraduate students, reporting prevalence rates ranging from 1.6 to $21.7 \%$ [1]. Whether it is actually addictive or not, social networking excessively and compulsively is unlikely to have positive effects over time, and can be defined, quite simply, as unhealthy $[2,21]$. In fact, the outcome of some research points to SNS addicts experiencing problems in the sphere of their emotions and social relations, and with their physical health and performance [42]. A disordered SNS use also seems to lead to a heightened susceptibility to substance and other addictions in undergraduate students [26]. In older adolescent populations, several studies have found associations between inappropriate substance use and a behavioral dependence apparently associated with spending too much time on Facebook [29], and a problematic Internet usage. For instance, when [31] examined Internet addiction and the factors associated with it in 1392 teenagers (13 to 18 years old), the use of alcohol emerged as a risk factor for a diagnosis of addiction to the Internet. This implies that substance use may be associated with problematic social networking sites usage (PSNSU). Recent research findings [50] also point to adolescents becoming addicted to Internet and experimenting with substance use having family-related issues in common. These may involve a more conflictual relationship with their parents, brothers and/or sisters who routinely drink alcohol, the impression that parents do not disapprove of adolescents drinking or smoking, and dysfunctional families generally. It seems reasonable to expect factors relating to the family domain that have anything to do with illegal substance use (such as a teenage sibling who drinks alcohol) to relate to PSNSU as well. Along much the same lines, the association between the experience of gambling and substance use (as demonstrated in earlier research by [15]), may be linked with PSNSU too.

The present study focused on seeking a link between PSNSU and substance use by young adolescents.

\section{Methods}

\section{Material and participants}

A survey called "Pinocchio" was implemented in the academic year 2013-2014 at several secondary schools in the city of Padua (north-east Italy), which has a population of young adolescents numbering around 8000. The study sample included 1325 pupils in years 6 to 8 (11- to 13-year-olds) at 8 different schools. To obtain a sample with an equal distribution in the area, one or two secondary schools from each of the 6 school districts in the city were recruited from among those volunteering to participate in a program conducted at their schools that focused on the prevention of underage drinking and smoking. The pupils anonymously answered a selfadministered, ad hoc questionnaire that was developed in the light of a previous study by [17], and presented to participants by a team managing the prevention program. Only pupils with objective difficulties (due to mental disability or a poor knowledge of the Italian language) for the purposes of understanding and answering the questionnaire were excluded.

For all the pupils enrolled, the parents were asked to give their written informed consent to their children's participation in the survey. The pupils' verbal assent was also required before they started to complete the baseline questionnaire. One hundred and six parents withheld their consent and their children were excluded. None of the pupils refused to take part in the study.

The questionnaire contained 106 multiple-choice items and touched on all the factors known to have a potential association with risks to behavioral health, i.e. social sphere and demographics, family setting, peers, personality, behavioral factors [8].

The variables measured for each domain entering the model as covariates are shown in Table 1; some variables were categorized as a dummy variables (shown in the same table). The "Gambling" variable was derived from answers of the section "Behavioral domain", to explicit questions referring to video poker, online betting, or scratch-and-win cards, as shown in Table 1. The substance use variables, shown in Table 2, are used to derive a latent factor measuring recent substance use, the values of the correlations between the variables are shown in Table 3.

The severity of any PSNSU was ascertained from the pupils' scores on 6 self-rated items, based on those used by Guzzo et al. [22] to investigate social network addiction disorder. More specifically, the questions listed in Table 2 each refer to one of six criteria of substance dependence as established by DSM-IV [18] (tolerance, withdrawal, use of increasing amounts, repeated attempts to quit, activities given up in order to use, too much time spent on use, physical problem related to use). 
Table 1 The questionnaire administered, divided into domains associated with health risk factors

\begin{tabular}{|c|c|c|}
\hline Domain risk factors & Variable name & Domain \\
\hline \multirow[t]{3}{*}{ Socio-demographic factors } & Age & How old are you? \\
\hline & Sex & Are you (male or female)? \\
\hline & Nationality & What's your nationality? \\
\hline \multirow[t]{10}{*}{ Family setting } & Separated parents & Do your parents live together? (Yes/No) \\
\hline & Father's alcohol consumption & $\begin{array}{l}\text { Does your father drink alcohol? (Never/Rarely/Once a month/ Once a week/ } \\
\text { Every day), after dichotomized as (Yes/No) }\end{array}$ \\
\hline & Father's smoking & Does your father smoke? (Yes/No) \\
\hline & Mother's alcohol consumption & $\begin{array}{l}\text { Does your mother drink alcohol? (Never/Rarely/Once a month/ Once a week/ } \\
\text { Every day) after dichotomized as (Yes/No) }\end{array}$ \\
\hline & Mother's smoking & Does your mother smoke? (Yes/No) \\
\hline & Sibling's alcohol consumption & $\begin{array}{l}\text { Does your sibling drink alcohol? (Never/Rarely/Once a month/ Once a week/ } \\
\text { Every day) after dichotomized as (Yes/No) }\end{array}$ \\
\hline & Sibling's smoking & Does your sibling smoke? (Yes/No) \\
\hline & Education & $\begin{array}{l}\text { How would you define the education that you have received from your parents } \\
\text { as regards obeying rules? (Flexible/Rigid/No rules) }\end{array}$ \\
\hline & Rules for returning home & $\begin{array}{l}\text { When you go out with friends, are you asked to be back by a certain time? } \\
\text { (Yes/No/l never go out with friends) }\end{array}$ \\
\hline & Weekly pocket money & Do you have weekly pocket money? (Yes/No) \\
\hline \multirow[t]{4}{*}{ Peer domain } & Size of group of friends & $\begin{array}{l}\text { How large is your group of friends? (No fixed group/2-4 friends/5-9 friends/ } \\
10-20 \text { friends/> } 20 \text { friends) }\end{array}$ \\
\hline & Decision-maker in group of friends & $\begin{array}{l}\text { Who makes decisions in your group of friends? ("I usually decide what we } \\
\text { do"/"We decide together"/ "Others decide for me") }\end{array}$ \\
\hline & Friends' alcohol consumption & $\begin{array}{l}\text { Do your friends drink alcohol? (Never/Rarely/Once a month/ Once a week/ } \\
\text { Every day) }\end{array}$ \\
\hline & Friends' smoking & Do your friends smoke? (Yes/No) \\
\hline \multirow[t]{6}{*}{ Personality domain } & Parish groups/Nolunteering/ Scouting & Do you often go to parish/volunteering/ scouting groups? (Yes/No) \\
\hline & Artistic activities & Do you engage in artistic activities? (Yes/No) \\
\hline & Playing sports & Do you play sports? (Yes/No) \\
\hline & Playing competitive sport & Do you play competitive sports? (Yes/No) \\
\hline & Obeying rules & $\begin{array}{l}\text { When people ask you to respect the rules: ("Always obeys the rules/No respect } \\
\text { for rules") }\end{array}$ \\
\hline & Average school mark & What are your average school marks across subjects? (4 or less/5/6/7/8/9/10) \\
\hline \multirow[t]{8}{*}{ Behavioral domain } & Hours of sleep & How many hours do you sleep at night? (5/6/7/8/9/10/More than 10) \\
\hline & Time of returning home in the evenings & $\begin{array}{l}\text { What time do you return home in the evening? }(18.00 / 19.00 / 20.00 / 21.00 / 22.00 / \\
23.00 / 24 / 00 / \text { After midnight) after dichotomized as From } 18 \text { to } 21: 59 \mathrm{~h} / \\
\text { After 22:00 } \mathrm{h}\end{array}$ \\
\hline & Text messages sent & $\begin{array}{l}\text { How many text messages do you send a day?(Number of text messages). } \\
\text { Categorized as: } 0-15 / 16-99 / 100-499 / \geq 500\end{array}$ \\
\hline & Hours spent playing with videogames & $\begin{array}{l}\text { On average, how many hours a day do you play with videogames? (Number } \\
\text { of hours) }\end{array}$ \\
\hline & Hours spent watching TV & On average, how many hours a day do you watch television? (Number of hours) \\
\hline & Scratch-and-win cards & Have you ever bought scratch and win cards? (Yes/No) \\
\hline & Video poker & Have you ever bet money at video poker? (Yes/No) \\
\hline & Online betting & Have you ever placed bets on the internet? (Yes/No) \\
\hline
\end{tabular}

Answers were given by means of a Likert scale (where 0 meant never, 1 meant rarely, 2 sometimes, 3 often, and 4 always). It was assumed that a pupil who reported a diagnostic criterion at least sometimes was affected by the corresponding symptom: since the DSM-IV declares that meeting 3 or more diagnostic criteria can be considered dependence, we dichotomized the variable PSNSU as having at least 3 such symptoms. We tested the scale's reliability coefficient using Cronbach's alpha: it amounted to 0.76 , which could be considered "acceptable". This 
Table 2 Definition of the variables Substance use and Problematic social networking site usage (PSNSU)

\begin{tabular}{ll}
\hline Variable & Question \\
\hline Substance use & Have you drunk an alcoholic beverage at least once in the last month? (Yes/No) \\
& Have you drunk an energy drink at least once in the last month? (Yes/No) \\
& Have you smoked at least once in the last month? (Yes/No) \\
& Do you ever stay up late and get up early in order to spend more time on social networking sites (Facebook, Netlog, \\
& Twitter,...)? \\
& Never/Rarely/Sometimes/Often/Always) \\
& Do you feel anxious if you cannot connect to the social network for a while? (Never/Rarely/Sometimes/Often/Always) \\
& Have you ever spent more time on social networking sites than you had intended? (Never/Rarely/Sometimes/Often/Always) \\
& Have you ever neglected homework, sports activities, time with friends, and so on, in order to spend more time on social \\
& networks? (Never/Rarely/Sometimes/Often/Always) \\
& How often do you try to cut down the amount of time you spend on social networks and fail? (Never/Rarely/Sometimes/ \\
& Often/Always) \\
& Have you ever thought, 'l'll carry on just for a few more minutes' when on social networks? (Never/Rarely/Sometimes/Often/ \\
& Always)
\end{tabular}

measure of PSNSU was adopted because there was no validated tool available for use with young Italian adolescents at the time of our study.

\section{Statistical methods}

First, we calculated proportions and 95\% confidence intervals of PSNS users.

Then a preliminary bivariate analysis was run to identify any variables that might be confounders. In particular, the $\chi^{2}$ test was applied to test the difference in how the categorical variables were distributed by PSNS usage, while Student's t-test was used to check for differences in the means of the continuous variables, again by PSNS usage.

A factor analysis was conducted using variables related to substance use, that is smoking, or energy drink or alcohol consumption, for measuring recent substance consumption. We, also, analyzed a polychoric correlation matrix to verify correlations between binary variables concerning smoking, or energy drink or alcohol consumption during the previous month.

The factor analysis revealed that only one factor had an eigenvalue larger than 1 (the eigenvalues were 1.57, -0.10 , and -0.18 for factors 1,2 , and 3 , respectively). The rotated factor loadings with Factor 1 for the different types of substance use are given in Table 3. The likelihood ratio test of independence against the saturated

Table 3 Correlations between variables and rotated factor loadings in the factor analysis

\begin{tabular}{lllll}
\hline & Correlation & & Factor \\
\cline { 2 - 3 } & Smoking & Energy drinks & Alcohol & 1 \\
\hline Smoking & 1,00 & & & 0.78 \\
Energy drinks & 0,33 & 1,00 & & 0.72 \\
Alcohol & 0,29 & 0,28 & 1,00 & 0.67 \\
\hline
\end{tabular}

model had a $p$ for the $x^{2}$ test $=<0.001$. To see whether it was appropriate to considering only one factor, we ran a confirmatory factor analysis. By constraining to 1 the parameter related to smoking, we obtained satisfactory goodness of fit indexes: the $p$-value related to the chi-square test was 0.15 , so we can accept the hypothesis of a good fit. Remarkably good values were also obtained for the Tucker-Lewis and the Comparative Fit indexes, which were 0.96 and 0.97 , respectively. The adjusted (0.92) and unadjusted (0.98) goodness of fit indexes were satisfactory too. The eight scores for the Factor 1 latent variable, measuring recent substance use, were then collapsed into three categories: no use (pupils who reported no consumption in the last month); medium-level use (pupils who used only one of the three substances in the last month); and high-level use (different combinations of use of more than one substance).

Finally, an ordered logistic regression was performed: the latent factor measuring recent substance use, categorized into three level, was entered as dependent variable, problematic SNS usage was considered as the independent variable, and the potential confounding factors as covariates. We also used the option to test the proportional odds (or parallel lines) assumptions for each variable, and we constrained the variables that met these assumptions.

The STATA software, ver. 12, was used for all the statistical analyses.

\section{Results}

Slightly more than half $(51.4 \%)$ of the 1325 pupils enrolled were boys, and most of the pupils (76.5\%) were Italian. The sample was a mean 12.4 years old (with a SD of 0.97 years).

Figure 1 shows, for each school year, the percentage of pupils classifiable as problematic SNS users. This 


\section{Social network sites problematic usage}

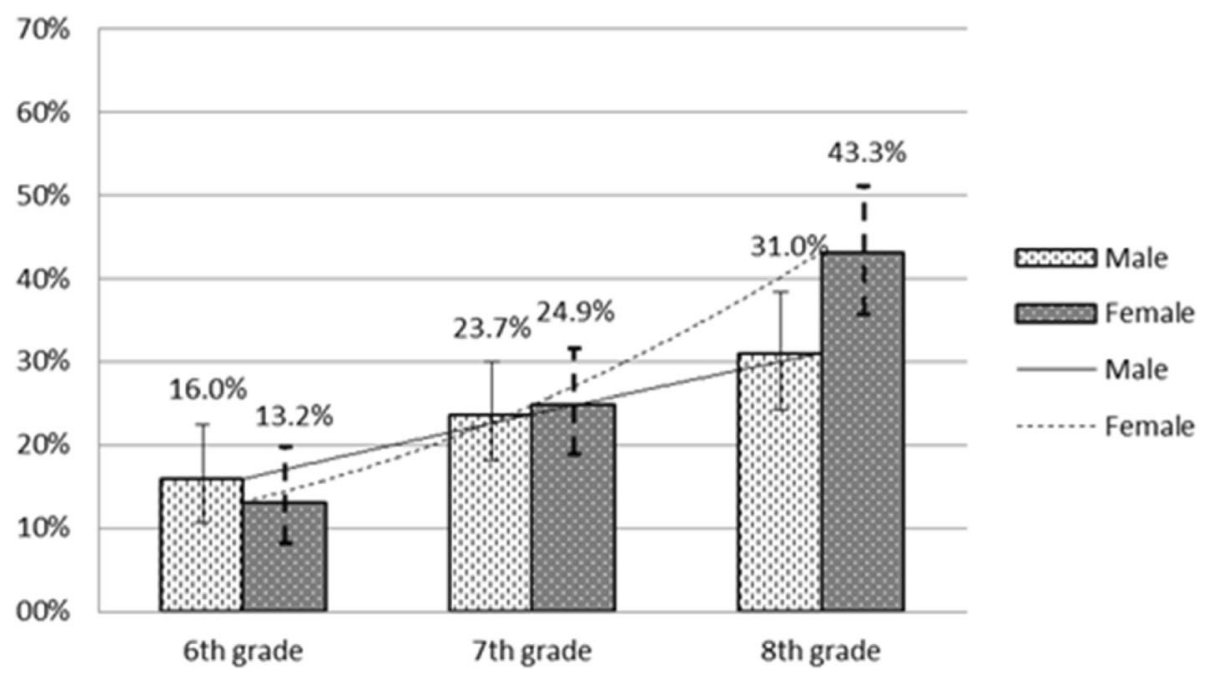

Fig. 1 Proportion (\%) of adolescents classified as problematic social networking site users (beyond the 75th percentile) by sex and school grade

percentage increased with age $(13.2 \%$ in year $6,24.9 \%$ in year 7 , and $43.3 \%$ in year 8 ), and girls were more affected than boys (with $16.0 \%, 23.7 \%$, and $31.0 \%$ in years 6,7 and 8 , respectively).

The adolescents who had smoked in the previous month amounted to $7.4 \%$ (95\%CI $6.0-8.9 \%)$ of the sample, while $14.7 \%$ (95\%CI $12.9-17.0$ ) had consumed energy drinks, and $18.3 \%$ (95\%CI 16.2-20.6\%) had drunk alcoholic beverages. An overall $72.2 \%$ of the pupils had used none of these substances in the previous month, while $18.6 \%$ had used one, $6.7 \%$ had used two, and $2.8 \%$ had used all three.

The results concerning the association between PSNSU and our study population's socio-demographic, family, personality, and behavioral characteristics are shown in Tables 4 and 5. Among the variables tested in the bivariate analysis, almost half of the young adolescents who sent 500 or more text messages a day, reported problematic use of SNS (47.5\%), amounting to about $18 \%$ more cases of self-reported PSNSU than among the individuals who sent 100-499 text messages a day (29.0\%), about $30 \%$ more than those who sent $16-$ 99 (19.3\%), and just over $40 \%$ more than those who sent up to 15 text messages a day (7.1\%). The proportion of cases of PSNSU among the adolescents who reported having bought scratch cards, or wagered money on video poker games, or placed bets on the Internet $(26.7 \%$ of the sample) was more than $10 \%$ higher than among the respondents not reporting any gambling behavior $(15.2 \%$ of the sample). The percentages of respondents with self-reported PSNSU were always higher among those who had reportedly smoked or consumed alcohol or energy drinks in the previous month than among those who had not, i.e.: $52.2 \%$ vs $16.5 \%$ for smoking; $35.4 \%$ vs $15.4 \%$ for alcohol; and $39.4 \%$ vs $15.5 \%$ for energy drinks. Table 6 shows the results of the ordered logistic regression. PSNSU was associated with a latent factor called 'recent substance use' in a fully-adjusted model $(p<$ $0.05)$. In other words, problematic SNS usage (OR 2.93; 95\% CI 1.77-4.85), having siblings (OR 4.81; 95\% CI $1.60-14.42)$, sending at least 500 text messages a day (OR 1.34; 95\% CI 1.02-1.76), and having experience of betting in internet, playing video poker or buying scratch cards (OR 2.47; 95\% CI 1.53-3.96) increased the likelihood of being a substance user with proportional odds, whereas attending parish group (OR 0.57; 95\% CI $0.35-$ $0.93)$ lowered the likelihood of this happening.

\section{Discussion}

This study demonstrates that young adolescents who are problematic SNS users are more likely to have recent experience of drinking alcoholic beverages, smoking or using energy drinks, after adjusting for socio-demographic factors, family, peers, personality, and behavioral risk factors that have already revealed a link with teenage substance use [22].

Research addressing this topic has been virtually non-existent to date [30], but our results are in line with the one other report [26] on PSNSU and substance misuse, which was a cross-sectional analysis conducted on university undergraduates. In their case, an excessive social networking site usage was positively associated with emotion regulating problems and drinking issues. The Authors concluded that a disordered SNS usage seems to be one of the signs of difficulties with regulating 
Table 4 Association of the socio-demographic, family domain, peer domain, personality domain, and behavioral domain factors with problematic social networking site usage (PSNSU)

\begin{tabular}{|c|c|c|c|c|}
\hline \multicolumn{2}{|l|}{ VARIABLES } & \multirow{2}{*}{$\frac{\text { MODALITIES }}{\text { Male }(n=653)}$} & \multirow{2}{*}{$\frac{\text { PSNSU Yes }(n=241)}{17.3 \%}$} & \multirow{2}{*}{$\frac{p}{0.085}$} \\
\hline SOCIO-DEMOGRAPHIC & Sex & & & \\
\hline & & Female $(n=591)$ & $21.2 \%$ & \\
\hline & Nationality & Italian ( $n=969)$ & $18.3 \%$ & 0.002 \\
\hline & & Not Italian $(n=204)$ & $27.9 \%$ & \\
\hline \multirow[t]{15}{*}{ FAMILY DOMAIN } & Father's alcohol consumption & Yes $(n=363)$ & $25.3 \%$ & $<0.001$ \\
\hline & & No $(n=842)$ & $16.3 \%$ & \\
\hline & Mother's alcohol consumption & Yes $(n=176)$ & $25.0 \%$ & 0.038 \\
\hline & & $\mathrm{No}(n=1031)$ & $18.3 \%$ & \\
\hline & Sibling's alcohol consumption & Yes $(n=42)$ & $38.1 \%$ & 0.001 \\
\hline & & No $(n=1005)$ & $18.0 \%$ & \\
\hline & Father's smoking & Yes $(n=291)$ & $26.1 \%$ & $<0.001$ \\
\hline & & No $(n=964)$ & $16.8 \%$ & \\
\hline & Mother's smoking & Yes $(n=183)$ & $23.5 \%$ & 0.093 \\
\hline & & No $(n=1075)$ & $18.2 \%$ & \\
\hline & Sibling's smoking & Yes $(n=88)$ & $33.0 \%$ & 0.001 \\
\hline & & No $(n=1012)$ & $18.0 \%$ & \\
\hline & Weekly pocket money & $1-10 € /$ week $(n=250)$ & $17.6 \%$ & 0.023 \\
\hline & & More than $10 € /$ week $(n=120)$ & $28.3 \%$ & \\
\hline & & No $(n=894)$ & $18.1 \%$ & \\
\hline \multirow[t]{4}{*}{ PEER DOMAIN } & Friends'smoking & Yes $(n=352)$ & $35.5 \%$ & $<0.001$ \\
\hline & & No $(n=896)$ & $12.6 \%$ & \\
\hline & Friends' alcohol consumption & Yes $(n=99)$ & $49.5 \%$ & $<0.001$ \\
\hline & & No $(n=1034)$ & $16.5 \%$ & \\
\hline \multirow[t]{10}{*}{ PERSONALITY DOMAIN } & Obeying rules & Always obeys the rules $(n=886)$ & $14.5 \%$ & $<0.001$ \\
\hline & & No respect for rules $(n=360)$ & $30.8 \%$ & \\
\hline & Parish groups & Yes $(n=752)$ & $16.1 \%$ & 0.002 \\
\hline & & No $(n=507)$ & $23.1 \%$ & \\
\hline & Volunteering & Yes $(n=174)$ & $19.9 \%$ & 0.086 \\
\hline & & No $(n=1081)$ & $14.4 \%$ & \\
\hline & Artistic activities & Yes $(n=403)$ & $15.4 \%$ & 0.024 \\
\hline & & No $(n=853)$ & $20.8 \%$ & \\
\hline & Playing sport & Yes $(n=1085)$ & $17.7 \%$ & 0.002 \\
\hline & & No $(n=177)$ & $27.7 \%$ & \\
\hline \multirow[t]{10}{*}{ BEHAVIORAL DOMAIN } & Returning home in the evenings & From 18 to $21: 59 \mathrm{~h}(n=665)$ & $21.2 \%$ & 0.028 \\
\hline & & After 22 h $(n=168)$ & $29.2 \%$ & \\
\hline & Hours of sleep & $>8 \mathrm{~h}(n=1066)$ & $15.9 \%$ & $<0.001$ \\
\hline & & $<8$ h $(n=195)$ & $36.9 \%$ & \\
\hline & Text messages sent & $0-15$ text messages $(n=297)$ & $7.1 \%$ & $<0.001$ \\
\hline & & $16-99$ text messages $(n=415)$ & $19.3 \%$ & \\
\hline & & 100-499 text messages $(n=314)$ & $29.0 \%$ & \\
\hline & & $\geq 500$ text messages $(n=80)$ & $47.5 \%$ & \\
\hline & Gambling & Yes $(n=419)$ & $26.7 \%$ & $<0.001$ \\
\hline & & No $(n=845)$ & $15.2 \%$ & \\
\hline
\end{tabular}


Table 4 Association of the socio-demographic, family domain, peer domain, personality domain, and behavioral domain factors with problematic social networking site usage (PSNSU) (Continued)

\begin{tabular}{|c|c|c|c|c|}
\hline VARIABLES & & MODALITIES & PSNSU Yes $(n=241)$ & $p$ \\
\hline & \multirow[t]{2}{*}{ Hours spent watching TV } & From 30 min to $2 \mathrm{~h} /$ day $(n=721)$ & $18.5 \%$ & \multirow[t]{2}{*}{0.009} \\
\hline & & More than 2 h / day $(n=333)$ & $23.7 \%$ & \\
\hline & \multirow[t]{2}{*}{ Smoking in the last month } & Yes $(n=90)$ & $52.2 \%$ & \multirow[t]{2}{*}{$<0.001$} \\
\hline & & No $(n=1175)$ & $16.5 \%$ & \\
\hline & \multirow[t]{2}{*}{ Alcohol consumption in the last month } & Yes $(n=229)$ & $35.4 \%$ & \multirow[t]{2}{*}{$<0.001$} \\
\hline & & No $(n=1036)$ & $15.4 \%$ & \\
\hline & \multirow[t]{2}{*}{ Energy drinks consumption in the last month } & Yes $(n=184)$ & $39.7 \%$ & \multirow[t]{2}{*}{$<0.001$} \\
\hline & & No $(n=1081)$ & $15.5 \%$ & \\
\hline
\end{tabular}

The following variables were tested and found unassociated $(p>0.10)$ with PSNSU (data not shown): Separated parents, Rules for returning home, Older sibling $>$ 13 years old, Size of group of friends, Decision-maker in group of friends, Hours spent playing with videogames, Education

emotions and a higher likelihood of substance abuse and addictions.

A possible explanation for the relationship observed in our study between PSNSU and substance consumption by adolescents can be sought in the amount of peer influence involved in social networking. Peer influence plays an important part in adolescence, as this is a time of life when individuals develop a new identity, make new friends, and join different peer groups. Meanwhile, their parents' influence tends to decrease [43]. Any adolescent's peers can be strongly influential, and friends may encourage each other to experiment with substances and take risks, exerting a normative pressure to do so [46]. Plenty of evidence has emerged of how a given adolescent's use of tobacco and alcohol is often linked to the use of these substances by their friends [6, 24]. Our data seem to point in this direction too, highlighting the association between having friends who drink alcohol and having smoked or consumed alcohol or energy drinks in the previous month. In addition, the analysis shows the relationship between having friends who drink alcohol and PSNSU, which could indicate that online exchanges with friends might mediate peer influence processes (as regards adolescent cigarette and alcohol use) by conveying information about peers' risk-taking behavior. [27] found that smoking and drinking by a sample of 10th-grade American students were significantly associated with having friends who posted pictures of partying or drinking online. The Authors concluded that an adolescent's risk-taking behavior was directly affected by exposure to online content, and significantly correlated with their friends' risk-taking behavior.
Online media often contain references to smoking and drinking, including descriptions and photographs of young people's drinking experiences [37]. Judging from a review of MySpace profiles, adolescents often boast of being familiar with adult-oriented behavior [23], such as smoking and alcohol drinking. When adolescents create and display social network content, this may be seen by their peers as a model to imitate, and social networks have the potential to strongly influence an adolescent's alcohol and tobacco use [13]. Applying social learning theories $[4,19,41]$ to modern media suggest that adolescents who see others drinking or smoking, and apparently suffering no unpleasant effects of their behavior, will be more inclined to follow suit. We also know from social learning theory that messages conveyed by the media concerning people's motives for certain behavior, and its pleasant associations and positive outcomes, are bound to have their appeal [41]. In another vein, the association between social networks and substance consumption can also be explained by the influence of marketing on the young. A social media case study [48] on a number of brands of alcoholic beverages found them abundantly present online, in content generated by marketers and users. The study described Facebook profiles in which advertisers and customers commented on these beverages, as well as competitions, videos, recipes, apps and games inciting viewers to engage with the marketers' content. For instance, Mart et al. counted more than 50,000 Facebook groups that had to do with alcohol in some way - over and above the alcohol manufacturers' direct marketing material [34]. There are promotions and events on the Facebook platform that relate to

Table 5 Means and standard deviations of variables by problematic social networking site usage (PSNSU) group

\begin{tabular}{llll}
\hline VARIABLE & PSNSU Yes $(n=276)$ & PSNSU No $(n=796)$ & $p$ \\
& Mean \pm SD & Mean \pm SD & $<0.001$ \\
\hline Age $(y r)$ & $12.62 \pm 0.99$ & $12.17 \pm 0.98$ & $<0.001$ \\
Average school marks & $6.97 \pm 1.02$ & $7.36 \pm 0.98$ & $<$ \\
\hline
\end{tabular}


Table 6 Ordered logistic regressions analysis of associations between recent substance use, derived from the latent variable, and problematic social networking site usage group: odds ratio and 95\% confidence intervals (Cl), $p$ value

\begin{tabular}{|c|c|c|c|c|}
\hline \multicolumn{2}{|c|}{ Recent substance (alcohol, cigarettes and energy drinks) use } & Odds ratio & {$[95 \% \mathrm{Cl}]$} & $p$ \\
\hline \multicolumn{5}{|c|}{ Significant Proportional Odds } \\
\hline \multicolumn{2}{|l|}{ Parish Group [ref. No] } & 0.57 & $0.35-0.93$ & 0.025 \\
\hline \multicolumn{2}{|c|}{$\geq 500$ text messages sent [ref. 0-15] } & 1.34 & $1.02-1.76$ & 0.038 \\
\hline \multicolumn{2}{|c|}{ Gambling Yes [ref. No] } & 2.47 & $1.53-3.96$ & 0.000 \\
\hline \multicolumn{2}{|c|}{ Siblings' alcohol consumption Yes [ref. No] } & 4.81 & $1.60-14.42$ & 0.005 \\
\hline \multicolumn{2}{|c|}{ Problematic social networking site usage Yes [ref. No] } & 2.93 & $1.77-4.85$ & 0.000 \\
\hline \multicolumn{5}{|c|}{ Significant Not Proportional Odds } \\
\hline \multirow[t]{5}{*}{ No vs Middle-High } & Male & 0.75 & $0.45-1.24$ & 0.256 \\
\hline & No obeying rules & 1.38 & $0.82-2.30$ & 0.224 \\
\hline & Hours of sleep $<8 \mathrm{~h}$ & 1.61 & $0.89-2.93$ & 0.117 \\
\hline & Weekly pocket money > 10 Euro & 0.92 & $0.63-1.33$ & 0.644 \\
\hline & Siblings' smoking Yes & 0.77 & $0.35-1.69$ & 0.522 \\
\hline \multirow[t]{5}{*}{ No-Middle vs High } & Male & 0.34 & $0.15-0.76$ & 0.009 \\
\hline & No obeying rules & 5.75 & $2.66-12.40$ & 0.000 \\
\hline & Hours of sleep $<8 \mathrm{~h}$ & 3.34 & $1.50-7.41$ & 0.003 \\
\hline & Weekly pocket money > 10 Euro & 2.06 & $1.25-3.39$ & 0.005 \\
\hline & Siblings' smoking Yes & 3.05 & $1.19-7.76$ & 0.020 \\
\hline
\end{tabular}

Cl confidence interval

The following variables were tested and found unassociated $(p<0.05)$ with recent substance use (data not shown): Age, Nationality, Artistic activities, Playing sport, Returning home in the evenings, Hours spent watching TV, Father's smoking, Friends' smoking, Father's alcohol consumption, Friends' alcohol consumption, Mother's alcohol consumption and Average school marks

alcohol brands [Freeman B, Chapman S], and - despite the World Health Organization's ban on all forms of tobacco advertising, promotion and sponsorship (in its Framework Convention on Tobacco Control), a study that checked for any such promotional activities by two British-American global tobacco brands on Facebook found more than 500 items across a variety of Facebook subsections [14].

On the other hand, the results of our study indicate that the affiliation to parish groups reduces the probability of adolescents experimenting with illicit substances. In our sample, the proportion of respondents with PSNSU was also lower among those who reported having a religious faith than among those who considered themselves atheists. These findings seem to suggest that, in early adolescence at least, religion has a part to play in helping children to mature and protecting them against risk-taking behavior [10]. In spite of the paucity of literature currently available on the topic, several reports have described how adolescents' religiousness relates to their risk-taking behavior. For instance, [32] found that religious affiliation helps to protect against delinquency, and [5] found a role for religion in preventing adolescent drug use. Other researchers noted that religious adolescents were less likely to abuse of marijuana or steroids, or to drive under the influence of alcohol [7, 47, 49].
Overall, our data bring to light an alarming picture, considering that most of the adolescents enrolled in our sample were not old enough to access Facebook, for instance, which establishes that members should be at least 13 years old [12]. Even greater cause for concern emerges from an Israeli study on how the parents of 195 Facebook users aged between 8 and 17 supervised their offspring's Internet usage. The Authors reported that these parents were less inclined to monitor their children's activities on Facebook than parents of older teenagers [9]. The researchers suggested that this was due to parents assuming that younger adolescents' online behavior would be more innocuous (playing games, chatting to friends) than might be the case of older teenagers $(13+)$. If this attitude is shared by the parents of most underage Facebook users, young adolescents would be more at risk than older teenagers (as the latter would be supervised by their parents) [25]. Our study confirmed the link between PSNSU and risk-taking behavior such as substance use at a very young age, highlighting the importance of SNS usage being included in schemes designed to prevent substance abuse and other risk-related behavior in early adolescence. A previous study $[16,18]$ had also shown that parents who supervise their children's media usage have the effect of safeguarding their academic, social, and physical development. Pediatricians and general physicians are in a good position to 
give families scientifically sound advice, and to urge parents to monitor their children's time on the Internet with care, as this can have far-reaching effects on their health.

When it comes to interpreting the results of the present research, a number of limitations need to be considered. For a start, this was a cross-sectional study, which makes it difficult to infer causality, especially as regards the one- or two-way direction of the association between substance use and PSNSU. Another weakness lies in that substance abuse is always a sensitive matter for adolescents, and our findings may be biased by their having exaggerated or played down their own behavior. We can assume, however, that this potential source of bias was contained by our use of a self-administered anonymous questionnaire. A third limitation concerns our requesting that respondents mention any alcohol drinking, cigarette smoking, or energy drink use in the previous month, so we also captured experimental sipping and puffing as well as more regular consumption patterns. This approach was used because, given the young age of our sample, any use at all (even in small quantities) is important: it can be seen as a challenge that draws young adolescents towards further risk behavior. That is why we preferred to adopt the type of question formulated by authors such as Peterson et al. [40], and to ask participants if they had drunk or smoked at all during the previous month. Other authors had also found it more useful to ask if respondents had ever engaged in a given undesirable behavior in the past, rather than whether they were doing so in the present, because past events are less threatening [44].

Be that as it may, our questions did not distinguish between substance use with and without parents' permission (such as a sip of wine for a toast at a birthday party), and it will be necessary to consider this issue in further studies [28].

\section{Conclusion}

In conclusion, this study revealed an association between PSNSU and other behavioral problems in young adolescents. Health promotion schemes that aim to intervene on several behavioral fronts should include the issue of PSNSU in this age group. When cases of an unhealthy use of social networking sites are identified, it is important to bear in mind that the approach to treating adolescent PSNSU should never involve total abstinence. Using the Internet has become an essential part of an adolescent's schooling and recreational culture. Efforts should focus on ensuring that their use of this medium (and especially of social networking sites) is kept under control. Relapsing PSNSU can be prevented by means of strategies developed in the setting of cognitive-behavioral therapies [11], such as those well described by [51]. These include, for example: (a) hindering adolescents' excessive Internet use by identifying their usage patterns and then disrupting them by rescheduling their spare time; (b) using external interferences in the form of events and activities that induce them to log off; (c) setting limits for the amount of time they are allowed to spend in Internet; (d) preventing them from accessing a particular application (beyond their control); (f) drawing up a list of all the things a given adolescent used to do before becoming too attached to Internet, such as sports, or hobby group activities.

\section{Abbreviations}

PSNSU: Problematic social networking site usage

\section{Acknowledgments}

The authors are grateful to all the schools in the province of Padua and the pupils who took part in the study.

\section{Ethical approval and consent to participation}

This study was approved by the Padova Teaching Hospital's Ethical Committee.

The pupils' participation in the study was subject to the consent of the directors of the schools involved. If approved, the prevention program then became part of the school's teaching plan, which has to be signed by parents at the beginning of each academic year. All parents of the pupils ultimately enrolled in the study then signed a consent form, and the pupils signed an assent form. Parents refused permission for their child to participate in $9.9 \%$ of cases. On the day when the questionnaires were administered, $89.4 \%$ of the pupils enrolled for the study were at school. All procedures complied with the ethical standards adopted by Padova Teaching Hospital, the Italian National Research Committee, the 1964 Helsinki Declaration and subsequent revisions thereof, or comparable ethical standards.

\section{Funding}

This study was financed by the Fondazione Cassa di Risparmio di Padova e Rovigo, a not-for-profit organization that, in the last two decades, has been promoting quality of life and sustainable growth in the Padua and Rovigo areas. The foundation took no part in the study's design, nor in any activities involved in the data collection, analysis, and interpretation, the drafting of this article or its submission for publication. All the schools in the province of Padua and the individual pupils who took part in the study are gratefully acknowledged.

\section{Availability of data and materials}

The data that were developed and analyzed in the present study are not publicly available. This is because they will be further analyzed by the authors and the foundation that supported their collection, to investigate other research hypotheses not yet explored. The dataset can nonetheless be obtained from the corresponding author on reasonable request.

\section{Authors' contributions}

LG conceived the study, coordinated its various phases, and approved the final manuscript as submitted. AB \& ES designed the study, ran the statistical analyses, reviewed and revised the manuscript, and approved the final version as submitted. SC designed the tools for data collection, managed data collection at the various schools, and approved the final manuscript as submitted. EM, CL and AT took part in data collection at the schools, and approved the final manuscript as submitted. LGP interpreted the findings, critically reviewed and revised the manuscript, and approved the final version as submitted. VB designed the sampling methods, critically reviewed and revised the manuscript, and approved the final version as submitted. MR completed further statistical analyses. All authors read and approved the final manuscript. 


\section{Competing interests}

The authors declare that they have no competing interest.

\section{Publisher's Note}

Springer Nature remains neutral with regard to jurisdictional claims in published maps and institutional affiliations.

\section{Author details}

'Department of Cardiologic, Vascular, Thoracic Sciences and Public Health, University of Padova, Via Loredan, 18, 35131 Padova, Italy. ${ }^{2}$ Novella Fronda Foundation for studies and applied clinical research in the field of addiction medicine, Padua, Italy. ${ }^{3}$ 2nd School of Hygiene and Preventive Medicine, University of Padova, Padova, Italy. ${ }^{4}$ Department of Surgery, Oncology and Gastroenterology, University of Padova, Padova, Italy. ${ }^{5}$ Department of Molecular Medicine; Laboratory of Public Health and Population Studies, Institute of Hygiene, University of Padova, Padova, Italy. ${ }^{6}$ Direttore, WHO Collaborating Centre Research \& Health Promotion on Alcohol and Alcohol-Related Health Problems, Rome, Italy. ${ }^{7}$ Centro Nazionale Dipendenze e Doping-National Centre on Addictions and Doping, Rome, Italy. ${ }^{8}$ Direttore, Osservatorio Nazionale Alcol - Director, National Observatory on Alcohol, Rome, Italy. 'Hygiene and Public Health Unit, University of Padova, Padova, Italy.

Received: 3 April 2017 Accepted: 19 October 2018

Published online: 23 November 2018

\section{References}

1. Alabi OF. A survey of Facebook addiction level among selected Nigerian University undergraduates. New Media Mass Commun. 2013;10:70-80.

2. Andreassen CS, Pallesen S. Social network site addiction - an overview. Curr Pharm Des. 2014;20:4053-61.

3. Andreassen CS. Online social network site addiction: a comprehensive review. Curr Addict Rep. 2015:2(2):175-84.

4. Bandura A. Social cognitive theory: an agentic perspective. Annu Rev Psychol. 2001;52:1-26.

5. Amey $\mathrm{CH}$, Albrecht SL, Miller MK. Racial differences in adolescent drug use: the impact of religion. Subst Use Misuse. 1996:31(10):1311-32.

6. Cruz JE, Emery RE, Turkheimer E. Peer network drinking predicts increased alcohol use from adolescence to early adulthood after controlling for genetic and shared environmental selection. Dev Psychol. 2012;48:1390e402.

7. Donahue MJ, Benson PL. Religion and the well-being of adolescents. J Soc Issues. 1995;51:145-60.

8. Donovan JE. Adolescent alcohol initiation: A review of psychosocial risk factors. J Adolesc Health. 2004;35(6):529.e7-18. https://doi.org/10.1016/j. jadohealth.2004.02.003

9. Dor A, Weimann-Saks D. Children's Facebook usage: parental awareness, attitudes and behavior. Stud Media Commun. 2012;1(1):1-14.

10. Ebstyne King P, Furrow JL. Religion as a resource for positive youth development: religion, social capital, and moral outcomes. Dev Psychol. 2004:40(5):703-13.

11. Echeburua E, de Corral P. Addiction to new technologies and to online social networking in young people: a new challenge. Adicciones. 2010;22: 91-5.

12. EU Kids Online: Social networking, age and privacy [Internet]. Scribd. http:// www.scribd.com/doc/60762478/EU-Kids-Online-Social-Networking-Age-andPrivacy. Accessed 20 Sept 2013.

13. Eyal K, Rubin AM. Viewer aggression and homophily, identification, and parasocial relationships with television characters. J Broadcast Electron Media. 2003:47(1):77-98.

14. Freeman B, Chapman S. British American tobacco on Facebook: undermining article 13 of the global World Health Organization Framework Convention on Tobacco Control. Tob Control. 2010;19(3):e1-e9. b.

15. Gallimberti L, Buja A, Chindamo S, et al. Experience with gambling in late childhood and early adolescence: implications for substance experimentation behavior. J Dev Behav Pediatr. 2016a;37(2):148-56.

16. Gallimberti L, Buja A, Chindamo S, Terraneo A, Marini E, Rabensteiner A, Vinelli A, Perez LJ, Baldo V. Problematic cell phone use for text messaging and substance abuse in early adolescence (11- to 13-year-olds). Eur J Pediatr. 2016b;175(3):355-64.

17. Gallimberti L, Chindamo S, Buja A, et al. Underage drinking on Saturday nights, sociodemographic and environmental risk factors: a cross-sectional study. Subst Abuse Treat Prev Policy. 2011;6:15. https://doi.org/10.1186/ 1747-597X-6-15

18. Gentile DA, Reimer RA, Nathanson Al, Walsh DA, Eisenmann JC. Al et al. protective effects of parental monitoring of children's media use: a prospective study. JAMA Pediatr. 2014;168(5):479-84.

19. Glanz K, Rimer B, Lewis F. Health behavior and health education: theory, research and practice. San Francisco: Wiley; 2002.

20. Griffiths MD, Kuss DJ, Demetrovics Z. Social networking addiction: an overview of preliminary findings. In: Rosenberg KP, Feder LC, editors. Behavioral addictions: criteria, evidence, and treatment. London: Academic; 2014. p. 119-41.

21. Griffiths MD. A components model of addiction within a biopsychosocial framework. J Subst Use. 2005:10:191-7.

22. Guzzo T, Ferri F, Grifoni P. Social network's effects on Italian teenager's life. J Next Generation Inf Technol. 2013:4(3):54.

23. Hinduja S, Patchin JW. Personal information of adolescents on the Internet: A quantitative content analysis of MySpace. J Adolesc. 2008;31(1):125-46 Epub 2007, Jul 2.

24. Hoffman $\mathrm{BR}$, Monge $\mathrm{PR}$, Chou $\mathrm{CP}$, et al. Perceived peer influence and peer selection on adolescent smoking. Addict Behav. 2007;32:1546e54.

25. Holloway D, Green L, Livingstone S. Zero to eight. Young children and their internet use. EU Kids Online: London; 2013.

26. Hormes JM, Kearns B, Timko CA. Craving Facebook? Behavioral addiction to online social networking and its association with emotion regulation deficits. Addiction. 2014;109(12):2079-88.

27. Huang GC, Unger JB, Soto D, Fujimoto K, Pentz MA, Jordan-Marsh M, Valente TW. Peer influences: the impact of online and offline friendship networks on adolescent smoking and alcohol use. J Adolesc Health. 2014; 54(5):508-14.

28. Kaplow JB, Curran PJ, Dodge KA. Child, parent, and peer predictors of earlyonset substance use: a multisite longitudinal study. J Abnorm Child Psychol. 2002:30(3):199-216.

29. Kittinger R, Correia CJ, Irons JG. Relationship between Facebook use and problematic internet use among college students. Cyberpsychol Behav Soc Netw. 2012;15(6):324-7.

30. Kuss DJ, Griffiths MD. Online social networking and addiction - a review of the psychological literature. Int J Environ Res Public Health. 2011;8(9): 3528-52.

31. Lam LT, Peng ZW, Mai JC, Jing J. Factors associated with internet addiction among adolescents. CyberPsychol. Behav. 2009;12:551-5.

32. Lerner RM, Galambos NL. Adolescent development: challenges and opportunities for research, programs, and policies. Annu Rev Psychol. 1998:49:413-46

33. Litt DM, Stock ML. Adolescent alcohol-related risk cognitions: the roles of social norms and social networking sites. Psychol Addict Behav. 2011;25(4):708.

34. Mart S, Mergendoller J, Simon M. Alcohol promotion on Facebook. The Journal of Global Drug Policy and Practice. 2009;3 (3). http://www. eatdrinkpolitics.com/wp-content/uploads/AlcoholPromotionFacebookSimon. pdf. Accessed 20 Nov 2015.

35. Mazibuko F. Drugs and young people: prevention and therapeutic models of intervention within the context of social development. Global Conference Poverty, Social Welfare and Social Development Challenges for the 21st Century. 29th ICSW International Conference on Social Welfare Cape Town, South Africa; 23-27 October 2000.

36. Montgomery $\mathrm{KC}$, Chester J. Interactive food and beverage marketing: targeting adolescents in the digital age. J Adolesc Health. 2009;45(Suppl 3): S18-29.

37. Moreno MA, Briner LR, Williams A, Brockman L, Walker L, Christakis DA. A content analysis of displayed alcohol references on a social networking web site. J Adolesc Health. 2010:47(2):168-75.

38. Moreno MA, Parks MR, Zimmerman FJ, Brito TE, Christakis DA. Display of health risk behaviors on MySpace by adolescents: prevalence and associations. Arch Pediatr Adolesc Med. 2009;163(1):27-34. https://doi.org/ 10.1001/archpediatrics.2008.528.

39. Pempek TA, Yermolayeva Y, Calvert SL. College students' social networking experiences on Facebook. J Appl Dev Psychol 2009; 30: 227-238. doi:https:// doi.org/10.1016/j.appdev .2008.12.010.

40. Peterson PL, Hawkins JD, Abbott RD, et al. Disentangling the effects of parental drinking, family management, and parental alcohol norms on current drinking by black and white adolescents. J Res Adolesc. 1994:4: 203-27. 
41. Primack BA, et al. Content analysis of tobacco, alcohol, and other drugs in popular music. Arch Pediatr Adolesc Med. 2008;162(2):169-75.

42. Ryan T, Chester A, Reece J, Xenos S. The uses and abuses of Facebook: a review of Facebook addiction. J Behav Addict. 2014;3:133-48.

43. Simons-Morton BG, Farhat T. Recent findings on peer group influences on adolescent smoking. J Prim Prev. 2010;31:191e208.

44. Sudman S, Bradburn NM. Asking questions: a practical guide to questionnaire design. San Francisco: Jossey-Bass Publishers; 1982

45. The Council on Communications and Media. Policy Statement - Children, Adolescents, Substance Abuse, and the Media. Pediatrics. 2010;126:791-9. www.pediatrics.org/cgi/doi/10.1542/peds.2010-1635. Accessed 1 Oct 2013.

46. Valente TW, Unger JB, Johnson CA. Do popular students smoke? The association between popularity and smoking among middle school students. J Adolesc Health. 2005;37:323e9.

47. Wallace JM Jr, Forman TA. Religion's role in promoting health and reducing risk among American youth. Health Educ Behav. 1998;25(6):721-41.

48. Winpenny E, Patil S, Elliott MN, van Dijk LV, Hinrichs S, Marteau T, Nolte E. Assessment of Young People's Exposure to Alcohol Marketing in Audiovisual and Online Media. London: European Commission; 2012.

49. Yarnold BM. Steroid use among Miami's public school students, 1992: alternative subcultures: religion and music versus peers and the "body cult". Psychol Rep. 1998:82(1):19-24.

50. Yen JY, Yen CF, Chen CC, Chen SH, Ko CH. Family factors of internet addiction and substance use experience in Taiwanese adolescents. CyberPsychol Behav. 2007;10:323-9.

51. Young KS. Internet Addiction: Symptoms, Evaluation, And Treatment Innovations in Clinical Practice [serial on the Internet]. 1999; 17 Available from: http: //treatmentcenters.com/downloads/ internet-addiction.pdf .

Ready to submit your research? Choose BMC and benefit from:

- fast, convenient online submission

- thorough peer review by experienced researchers in your field

- rapid publication on acceptance

- support for research data, including large and complex data types

- gold Open Access which fosters wider collaboration and increased citations

- maximum visibility for your research: over $100 \mathrm{M}$ website views per year

At $\mathrm{BMC}$, research is always in progress.

Learn more biomedcentral.com/submissions 